\title{
Results of Treatment of Squamous Cell Carcinoma of Maxillary Sinus: A 26-Year Experience
}

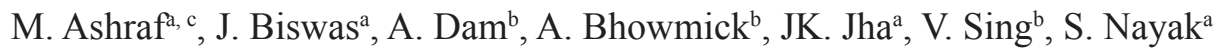

\begin{abstract}
Background: Five-year survival in squamous cell carcinoma of maxillary antrum is low. This article examines the results of various approaches to treatment as given in our hospital in past 26 years.
\end{abstract}

Methods: From 1979 to 2005, 379 patients with squamous cell carcinoma of maxillary antrum managed with curative intent were studied. Twenty-eight patients had T2, 237 patients had T3, and 114 had T4 tumors. The N classification was N0 in 316 patients, N1 in 21 patients, N2a in 28 patients and N2b in 14 patients. Treatment to the primary site comprised of surgery $(\mathrm{Sx})$ and radiation therapy (RT) in 284 patients, RT alone in 57 patients and chemotherapy (CTx) with radiotherapy in 38 patients.

Results: There was a difference in survival between patients who underwent Sx with RT compared with patients who received RT alone or CTx with RT. The most common pattern of recurrence was in the primary site, $187(49.3 \%)$ patients. Local control at 3 and 5 years was $71 \%$ and $63.8 \%$ respectively in Sx with RT, $31.6 \%$ and $28 \%$ respectively in RT, and $28.9 \%$ and $26 \%$ in CTx with RT group.

Conclusions: The type of treatment to the primary site is an important determinant of survival and local control. Surgery with radiation is a better treatment option.

Keywords: Squamous; Antrum; Maxillary; Second primary

Manuscript accepted for publication February 11, 2010

${ }^{\mathrm{a} D e p a r t m e n t ~ o f ~ S u r g i c a l ~ O n c o l o g y, ~ C h i t t a r a n j a n ~ N a t i o n a l ~ C a n c e r ~ I n s t i ~}$ tute (CNCI), 37, S P Mukherjee Road, Kolkata-26, India

${ }^{\mathrm{b}}$ Department of Head and Neck Surgery, Chittaranjan National Cancer Institute (CNCI), 37, S P Mukherjee Road, Kolkata-26, India

${ }^{\mathrm{c} C o r r e s p o n d i n g ~ a u t h o r: ~ K r i s h n a ~ S u d h a ~ A p a r t m e n t s, ~ 28, ~ C h a r u ~ A v e n u e, ~}$ Kolkata-33, India. E-mail: aashob@gmail.com; ashraf_qz@yahoo. co.in

doi:10.4021/wjon2010.02.191w

\section{Introduction}

Maxillary sinus cancer is relatively rare neoplasm, with an incidence representing a small percentage $(0.2 \%)$ of human malignant tumours and only $1.5 \%$ of all head and neck malignant neoplasms $[1,2]$. Because of the relative rarity of carcinoma of the maxillary sinus, institutional experience is usually limited. The incidence seems to vary in different parts of the world, with Asian countries reporting high numbers of cases [3-5]. However, the experience with regard to the incidence and presentation in Western Europe and the United States is similar. Carcinomas of the maxillary sinus comprise nearly $80 \%$ of all cases of paranasal sinus tumors [6-9]. In a fairly good majority of patients, this cancer is diagnosed in advanced stages, making it difficult to determine the origin of the neoplasm [9]. Although the majority of maxillary sinus carcinomas are locally advanced at diagnosis because its symptoms are nonspecific and resemble sinusitis [2], yet these tumours tend to remain localized to maxilla for a long time and during evolution they invade adjacent structures such as bone, base of the skull, facial soft tissue, oral cavity, and orbits[2, 6, 7, 10-13]. Treatment of these tumors has included either surgery, radiation therapy, or a combination of both. Nevertheless, in more advanced stages, both surgery and radiotherapy have limitations $[2,6,9,14]$. The purpose of this article was to review our experience with maxillary sinus carcinoma and to examine the results of various approaches to treatment as given in our hospital.

\section{Materials and Methods}

\section{Patients and tumor characteristics}

From 1979 to 2005, 379 patients with squamous cell carcinoma of maxillary antrum were managed with curative intent in the departments of surgical oncology, ENT and radiation oncology of Chittaranjan National Cancer Institute, Kolkata, India. There were $274(72.2 \%)$ male and $105(27.8 \%)$ female patients with a mean age of 47.2 years (range $23-67$ years). Tumor was on the right side in $236(62.2 \%)$ patients 
and on the left side in $143(37.8 \%)$ patients. The location of the neoplasm was suprastructure only in $69(18.2 \%)$ patients, infrastructure only in $142(37.5 \%)$ patients, and both in $168(44.3 \%)$ patients .The tumors were well differentiated in $132(34.9 \%)$ patients, moderately differentiated in $182(48 \%)$ patients, and poorly differentiated in $65(17.1 \%)$ patients. All tumors were radiologically assessed. Between 1979 and 1987, tomograms were used. Since 1988, computerized tomography $(\mathrm{CT})$ had been introduced, and since 1991, magnetic resonance imaging (MRI) has been utilized, specifically in cases where additional information with regard to soft tissue extension, such as in the orbit or retromaxillary and intracranial regions, was required. Tumor extension was found on an average of 1.4 adjacent sites (range 1 to 4 adjacent sites). Frequency of invasion was highest into the tissue underlying the skin (134 patients, 35\%) followed by involvement of ethmoid sinuses (98 patients, $25.8 \%$ ) and skin of the cheek (95 patients, 25\%). Tumor extended to the orbit in 37 patients $(9.8 \%)$, eye in 34 patients $(9 \%)$, cribriform plate in 52 patients (13.7\%), pterygoid fossa in 55 patients $(14.5 \%)$, sphenoid sinus in 26 patients $(6.8 \%)$, and infra temporal fossa in 26 patients $(6.8 \%)$. Tumors were classified retrospectively using the American Joint Committee on Cancer Staging System [15]; tumor classification was T1 in 0 patients, $\mathrm{T} 2$ in 28 patients, $\mathrm{T} 3$ in 237 patients, and T4a in 114 patients (Table 1). Lymph nodes were positive in 63 patients (16.6\%). N classification was N0 in 316 patients, $\mathrm{N} 1$ in 21 patients, N2a in 28 patients, N2b in 14 patients, and no patient had $\mathrm{N} 2 \mathrm{c}$ nodes.

Treatment to the primary site comprised surgery and radiation therapy in 284 patients, radiation therapy alone in 57 patients and a combination of chemotherapy and radiation in 38 patients. Indications for nonsurgical therapies were patients' age, medical status including surgical risk, and the pa- tients' choice, the later being the predominant factor which decided the nature of treatment. Chemotherapy consisted of methotrexate and/or bleomycin and/or cisplatin, three to four courses, followed by megavoltage radiotherapy in daily doses of 2 Gray, 5 days a week, to a total of 60 to 65 Gray in 30 to 32 sittings. Radiation was delivered through two wedge pair or three fields (one anterior and two laterals) with customized blocks to prevent irradiation of normal tissues, with special attention to the orbital contents and the optic nerve. The median dose to the primary site for patients treated with radiotherapy alone was 7000 cGy using fractions of $180-200$ cGy. The regional lymph nodes were treated only in patients with neck involvement. The tumor and neck stage for patients undergoing surgery and radiation therapy, chemotherapy with radiotherapy and radiotherapy alone is presented in Table 1 . In the patients who underwent surgery $(n=284)$, 225 received postoperative radiotherapy and 59 received preoperative radiotherapy. Surgical resection was described as a total maxillectomy in 196 patients, partial maxillectomy in 63 patients, completion maxillectomy in 25 patients and local excision of recurrent nodules in 39 patients. 34 patients underwent an orbital exenteration and 63 underwent a neck dissection. For patients receiving postoperative irradiation, radiotherapy usually was started 3 - 6 weeks after surgery. The dose to the primary site for patients receiving postoperative radiotherapy was 5500 centigray (cGy) for tumors with margins more than $1 \mathrm{~cm}$ free of tumor, $6000 \mathrm{cGy}$ for tumors with less than $1 \mathrm{~cm}$ margin free of disease, and $6600 \mathrm{cGy}$ for tumors with positive margins. For patients receiving preoperative radiotherapy the dose was $5000 \mathrm{cGy}$.

\section{Statistical analysis and follow-up}

For calculation of survival and local control, endpoints were

Table 1. Tumor and Lymph Node Stage in 379 Patients With Maxillary Sinus Carcinoma According to Treatment of the Primary Site

\begin{tabular}{|c|c|c|c|c|c|}
\hline Stage & $\begin{array}{l}\text { Sx and RT* } \\
\text { (no. of patients) }\end{array}$ & $\begin{array}{l}\text { RT and Sx* } \\
\text { (no. of patients) }\end{array}$ & $\begin{array}{l}\text { RT } \\
\text { (no. of patients) }\end{array}$ & $\begin{array}{l}\mathrm{CT} x^{*} \text { and } \mathrm{RT} \\
\text { (no. of patients) }\end{array}$ & Total \\
\hline T2N0 & 18 & 0 & 10 & 0 & 28 \\
\hline T3N0 & 151 & 25 & 38 & 2 & 216 \\
\hline T3N1 & 4 & 13 & 0 & 4 & 21 \\
\hline T4N0 & 16 & 14 & 19 & 23 & 72 \\
\hline $\mathrm{T} 4 \mathrm{~N} 1$ & 0 & 0 & 0 & 0 & 0 \\
\hline T4N2a & 12 & 7 & 0 & 9 & 28 \\
\hline $\mathrm{T} 4 \mathrm{~N} 2 \mathrm{~b}$ & 14 & 0 & 0 & 0 & 14 \\
\hline Total & $225(59.4 \%)$ & $59(15.6 \%)$ & $57(15 \%)$ & $38(10 \%)$ & $379(100 \%)$ \\
\hline
\end{tabular}

*Abbreviations: Sx - Surgery; RT - Radiation Therapy; CTx - Chemotherapy. 
Table 2. Survival and Local Control Data According to Treatment of the Primary Site

\begin{tabular}{|c|c|c|c|c|c|}
\hline \multirow[t]{2}{*}{ Treatment } & \multicolumn{2}{|c|}{ 3-year } & \multicolumn{2}{|c|}{ 5-year } & \multirow{2}{*}{$\begin{array}{l}\text { 10-year } \\
\text { Survival (\%) }\end{array}$} \\
\hline & Survival (\%) & Local control (\%) & Survival (\%) & Local control (\%) & \\
\hline $\begin{array}{l}\mathrm{Sx} \text { and } \mathrm{RT}^{*} \\
(\mathrm{n}=225)\end{array}$ & $69 \%$ & $71 \%$ & $63.5 \%$ & $65.8 \%$ & $48 \%$ \\
\hline $\begin{array}{l}\text { RT and } \mathrm{Sx}^{*} \\
(\mathrm{n}=59)\end{array}$ & $54.3 \%$ & $50 \%$ & $47 \%$ & $38.9 \%$ & $27 \%$ \\
\hline $\begin{array}{l}\text { CTx* and RT } \\
(\mathrm{n}=38)\end{array}$ & $47.4 \%$ & $28.9 \%$ & $34 \%$ & $26.3 \%$ & $13 \%$ \\
\hline $\mathrm{RT}(\mathrm{n}=57)$ & $47 \%$ & $31.6 \%$ & $31 \%$ & $28 \%$ & $19 \%$ \\
\hline
\end{tabular}

*Abbreviations: Sx - Surgery; RT - Radiation Therapy; CTx - Chemotherapy.

determined from the date of diagnosis until the event of interest. For survival, the event of interest was death. For disease free survival, the event of interest was local, regional, or distant failure. For local control, the event of interest was local failure. The mean and median follow-up times were 93 and 67 months, respectively (range 37 - 365 months).

\section{Results}

\section{Survival}

The 3-, 5-, and 10-year overall survival rates of patients with maxillary sinus carcinoma were $61.5 \%, 53 \%$ and $36.9 \%$ respectively. For patients who underwent surgery and postoperative radiation therapy, the 3-, 5- and 10-year overall survival rates were $69 \%, 63.5 \%$ and $48 \%$ respectively. For patients who received preoperative radiotherapy and surgery, the 3- and 5-year survival rates were 54.3\% and $47 \%$ respectively, and the 10-year survival rate was $27 \%$. For patients who received radiation therapy alone, the 3- and 5 -year survival rates were $47 \%$ and $31 \%$ respectively, and 10 -year survival rate was $19 \%$. For patients who received chemotherapy and radiation, the 3- and 5-year survival were $47.4 \%$ and $34 \%$ respectively, and the 10 -year survival was $13 \%$. Comparison of overall survival according to treatment to the primary site is shown in Table 2 .

\section{Patterns of recurrence}

The patterns of recurrence for all 379 patients were as follows: the most common site of recurrence was in the primary site, which was observed in 187 of 379 patients (49\%); failure in the regional lymph nodes and distant sites were observed in 96 (25\%) and $43(11.4 \%)$ patients respectively; isolated local failure was the most common pattern of recurrence, as demonstrated in 107 of 379 patients $(28.2 \%)$.

\section{Local control}

The 3-, 5-, and 10-year actuarial estimates of local control for all patients were $57.8 \%, 52 \%$ and $44.2 \%$ respectively. For patients who underwent surgery and postoperative radiation therapy, the 3-and 5-year local control rates were $71 \%$ and $65.8 \%$ respectively; for patients who received preoperative radiation therapy and surgery, the 3- and 5-year local control rates were $50 \%$ and $38.9 \%$ respectively; for patients who received chemotherapy and radiation, the 3- and 5-year local control rates were $28.9 \%$ and $26.3 \%$ respectively; and for patients who received radiation therapy alone, the 3- and 5 -year local control rates were $31.6 \%$ and $28 \%$ respectively. There was a statistically significant $(\mathrm{p}=0.0002)$ difference in local control rates between surgery with postoperative radiotherapy and other (radiotherapy alone, chemotherapy with radiation, and preoperative radiation followed by surgery) groups.

\section{Complications}

There were a total of 196 documented complications. The most common type of complication was the formation of fistulae, which were found in $73(19.3 \%)$ patients, of which 38 were from the group of patients who had received preoperative radiation therapy $(n=59,64 \%)$ and 35 patients from the group who had received postoperative radiation and developed oro-cutaneous fistula $(\mathrm{n}=225,15.6 \%)$. Thirty-seven patients $(9.7 \%)$ developed cataracts, 10 patients $(2.6 \%)$ developed retinopathy, 23 patients $(6 \%)$ developed epiphora, 12 patients $(3.2 \%)$ developed nasal obstruction, and 5 patients $(1.3 \%)$ developed cellulitis. Osteoradionecrosis of the 
orbital wall was found on average 6.6 years (range 3 to 9 years) after radiotherapy in 8 patients $(2 \%)$.

\section{Second cancers}

Second primary tumors were documented in 19 (5\%) patients. Four patients had poorly differentiated, 8 patients had well differentiated and 7 patients had moderately well differentiated squamous cell cancers on histopathology. In 9 out of these 19 patients, the tumors arose in the gingivo-buccal sulcus, in 5 patients from dorsal tongue, and in 3 patients from larynx. In one patient each tumor arose from floor of the mouth and tonsil. Average interval from the time of diagnosis of primary tumor and the appearance of second primary malignancy was 7.68 years (range 4.5 to 11.5 years). All these patients had received radiation ranging from $5500 \mathrm{cGy}$ to $7000 \mathrm{cGy}$. T staging of these tumors was T2 in 14 patients and T1 in 5 patients. All were managed by surgery .There was no mortality associated with second primary tumors.

\section{Discussion}

Maxillary sinus carcinoma presents a therapeutic challenge to both the surgeon and the radiation oncologist. Because symptoms are vague and nonspecific, the majority of carcinomas are diagnosed as locally advanced disease [2]. Extension to contiguous structures including the orbit, ethmoid sinus, sphenoid sinus, nasal cavity, nasopharynx, pterygoid fossa, palate and cheek may occur and can be a potential problem in the surgical and/or radiotherapeutic management of this disease [2, 9]. In our study, frequency of invasion was highest into the tissue underlying the skin (134 patients, $35 \%$ ) followed by involvement of ethmoid sinuses (98 patients, 25.8\%) and skin of the cheek (95 patients, 25\%). Tumors were predominantly T3 or T4 as observed in 351 of 379 patients $(92.6 \%)$. Similar incidence has been presented from other parts of the world [4, 5, 8, 9]. Sakai et al [3] reported a series of 773 patients with maxillary sinus carcinoma seen in a 22-year period between 1959 and 1979. Rifki [4] reported that carcinoma of the maxillary sinus in Indonesia is the second most common malignancy in the head and neck, only next to nasopharyngeal carcinoma. From India, Sharma et al [5] reported 226 cases of carcinoma of the maxillary sinus in a 10 -year period. The same authors reported a $40.7 \%$ incidence of cervical nodal metastasis at first presentation. In our study lymph nodes were positive in 63 patients $(16.6 \%)$. Most series report an incidence of about $10 \%$ (range $7 \%$ to $22 \%$ ) of nodal metastasis in the cancer of maxillary antrum $[11,16,17]$. The striking difference in incidence and mode of presentation of patients, guess Tiwari et al [18], in western countries and some Asian and African countries suggests that we are dealing with a histologically similar tumor with different biological behavior. It may be that the etiological factors between the two groups are also different.

Local recurrence is an important cause of failure of the curative treatment of maxillary sinus carcinoma $[2,18,19]$. Pattern of failure analysis in 379 consecutive patients seen at our institution for curative treatment revealed that $49 \%$ of patients failed at the primary site. Isolated local failure occurred in $28.2 \%$ of patients and was the most common pattern of recurrence. Therefore, strategies to improve local control are imperative in the management of this disease. Analysis of the treatment characteristics in the local control of maxillary sinus carcinoma revealed that the type of treatment to the primary site was a significant variable. Patients who underwent a combination of surgery and adjuvant radiation therapy had a 5-year local control rate of $63.8 \%$ compared with $38.9 \%, 28 \%$, and only $26 \%$ respectively, for those who received neoadjuvant radiation therapy and surgery, radiation alone, and a combination of chemotherapy and radiation. Table 2 shows the local control rates in different series in patients who underwent surgery and radiation therapy versus patients who received radiation therapy alone and chemotherapy with radiation. In general, our results are comparable to the reported results of other authors in that, the treatment by surgery and radiation therapy yields local control rates of $53-78 \%$ whereas local control after radiation therapy alone ranges from $14 \%$ to $55 \%[2,6,9-11,16$, 20-22].

Considering the retrospective nature of our study and a relatively small number of patients $(n=59)$ who received preoperative radiation, the question of whether radiation therapy should be given before or after surgical resection cannot be addressed definitively in our study. Radiation therapy has been proposed to be given preoperatively because the blood supply to the tumor remains intact and hence tumor hypoxia is less of a problem, at least theoretically. Yu Hua et al [23] reported a 64\% 5-year survival rate in the preoperative radiation therapy group and a 5-year survival rate of $26 \%$ in the postoperative radiation therapy group. The report suggests that the complication rate was higher in the preoperative group compared with patients who received postoperative radiation therapy (29\% versus 14\%). Older studies like that of Jesse, however, report no difference in local control or survival. In a comparative study by Jesse, of preoperative and postoperative radiation therapy in patients with squamous cell carcinoma of the paranasal sinuses, patients who were treated with preoperative radiation therapy had a higher morbidity rate [24]. A more recent report by Guo et al, from China, supports the use of postoperative irradiation and shows a 5-year survival rate of 50.8\% in 151 patients with maxillary sinus carcinoma [25]. Our results indicate a lower 5-year local control rate $(38.9 \%, \mathrm{n}=59)$ and higher postoperative complication rate (64\% fistula rate) in preoperative radiation group of patients as compared to 5 -year local control rate of $63.8 \%(n=225)$ and postoperative complication rate of $15.6 \%$ (oro-cutaneous fistulae) in 
postoperative radiation group.

Chemotherapy in the form of Cisplatin was introduced only in the 1980s [26]. Until that time, Methotrexate was the drug used in squamous cell carcinoma. Extensive use of combination chemotherapy with radiotherapy and limited surgery has been reported, especially in Japanese literature, but has not made significant impact in the treatment of squamous cell carcinoma [27-29]. Our study did not show any benefit of anterior chemotherapy followed by radiation in squamous cancer of maxillary antrum. It showed 5-year local control rate of only $26.3 \%$ in patients who received chemotherapy followed by radiation, as compared to $28 \%$ local control rate for radiation alone and $63.8 \% 5$-year local control rate for a combination of surgery and radiation.

Among patients with head and neck cancer, more are alleged to die from second tumours than from their original disease $[30,31]$. The risk of a second primary tumour is thought to be independent of the stage of the first tumor and seems to be no greater in men than in women, but whether it is influenced by the site of the primary tumour remains controversial [32-34]. The greatest risk, however, seems to be the continued use of alcohol and tobacco though opinion varies about which one is more influential. Wynder et al [35] found tobacco but not alcohol to be associated with an increased risk. They also report, however, that stopping both smoking and drinking did not prevent further tumours from developing, although Moore[36] showed a decreased incidence when smoking ceased. Moore also noted a greater risk of second malignant tumours with continued smoking [36]. Others also have found that smoking and drinking together seem to increase the risk of second malignant tumours $[32,34,35]$. Furthermore, the longer the patients survive, the more likely they are to develop another tumour $[30,36]$. Odgen et al documented that normal oral mucosa exposed to ionizing radiation during the treatment of orofacial tumours displays abnormal DNA profiles [37]. Although these changes returned to the normal diploid state within six weeks after completing treatment, the potential for latent radiation damage remains [38-40]. This may explain why after five years the incidence of second malignant tumours seems to be greater in those who received radiotherapy [30]. The tumour itself may exercise an effect on the regional mucosa. Slaughter et al first described the concept of field cancerization [40], and research using exfoliative cytology has identified evidence for field change within the normal oral mucosa of patients with oral cancer even in those who do not smoke or drink alcohol [41]. In our study, we found second primary tumors in $19(5 \%)$ patients. All these patients had received radiation ranging from $5500 \mathrm{cGy}$ to $7000 \mathrm{cGy}$. Average interval from the time of diagnosis of primary tumor and the appearance of second primary malignancy was 7.68 years (range 4.5 to 11.5 years). Commonest location of these tumors was the gingivo-buccal area (9 patients), and floor of mouth and tonsil were least common locations (1 each site).
Dorsal tongue was the second most common site with 5 tumors and larynx was the third most common site (3 tumors). No mortality was immediately associated with second primary cancers in our series. This was due to the fact that all tumors were diagnosed at a relatively early stage because of a regular follow-up.

Keeping in view the limitations of a retrospective study, a definitive recommendation can not be made based on our study. However, the results of the current study regarding the treatment of squamous cell carcinoma of the maxillary sinus show the superiority of surgery and postoperative radiation therapy as compared with preoperative radiation and surgery, radiation therapy alone or chemotherapy followed by radiotherapy. For patients who cannot undergo surgical resection, radiation therapy alone can be used; however, our results indicate a local control rate of only $28 \%$ at 5 years.

\section{Acknowledgements}

We gratefully acknowledge the help of Dr. S. Mandal, Head of the department of medical records of our institution, for his statistical work. We are obliged to Dr. N. Alam, Dr. D. P. Nanda, Dr. R. Saha for their help in manuscript preparation.

\section{Conflict of Interest}

The authors have no conflict of interest.

\section{References}

1. Nunez F, Suarez C, Alvarez I, Losa JL, Barthe P, Fresno M. Sino-nasal adenocarcinoma: epidemiological and clinico-pathological study of 34 cases. J Otolaryngol 1993;22(2):86-90.

2. Paulino AC, Marks JE, Bricker P, Melian E, Reddy SP, Emami B. Results of treatment of patients with maxillary sinus carcinoma. Cancer 1998;83(3):457-465.

3. Sakai S, Hohki A, Fuchihata H, Tanaka Y. Multidisciplinary treatment of maxillary sinus carcinoma. Cancer 1983;52(8):1360-1364.

4. Rifki N. Problems of paranasal sinus malignancy in Indonesia. ORL Indonesia 1985; 16:175-180.

5. Sharma S, Sharma SC, Singhal S, et al. Carcinoma of the Maxillary antrum. A 10-year experience. Ind J Otolaryngol 1991; 43:191-194.

6. Bristol IJ, Ahamad A, Garden AS, Morrison WH, Hanna EY, Papadimitrakopoulou VA, Rosenthal DI, et al. Postoperative radiotherapy for maxillary sinus cancer: longterm outcomes and toxicities of treatment. Int J Radiat Oncol Biol Phys 2007;68(3):719-730.

7. Roush GC. Epidemiology of cancer of the nose and 
paranasal sinuses: current concepts. Head Neck Surg 1979;2(1):3-11.

8. Silverberg E, Grant RN. Cancer statistics, 1970. CA Cancer J Clin 1970;20(1):11-23.

9. Manrique RD, Deive LG, Uehara MA, Manrique RK, Rodriguez JL, Santidrian C. [Maxillary sinus cancer review in 23 patients treated with postoperative radiotherapy]. Acta Otorrinolaringol Esp 2008;59(1):6-10.

10. Ahmad K, Cordoba RB, Fayos JV. Squamous cell carcinoma of the maxillary sinus. Arch Otolaryngol 1981;107(1):48-51.

11. Amendola BE, Eisert D, Hazra TA, King ER. Carcinoma of the maxillary antrum: surgery of radiation therapy? Int J Radiat Oncol Biol Phys 1981;7(6):743-746.

12. Boone LM, Harbe TH. Malignant disease of paranasal sinuses and the nasal cavity. AJR Am J Roentgenol. 1968; 102:627-38.

13. Frich JC. Treatment of advance squamous cell carcinoma of the maxillary sinus. Int J Radiat Oncol. 1982;8:14529.

14. Hoppe BS, Stegman LD, Zelefsky MJ, Rosenzweig KE, Wolden SL, Patel SG, Shah JP, et al. Treatment of nasal cavity and paranasal sinus cancer with modern radiotherapy techniques in the postoperative setting-the MSKCC experience. Int J Radiat Oncol Biol Phys 2007;67(3):691-702.

15. American Joint Committee on Cancer. Manual for staging of cancer. Philadelphia: J.B. Lippincott, 2002.

16. Jiang GL, Ang KK, Peters LJ, Wendt CD, Oswald MJ, Goepfert H. Maxillary sinus carcinomas: natural history and results of postoperative radiotherapy. Radiother Oncol 1991;21(3):193-200.

17. Paulino AC, Fisher SG, Marks JE. Is prophylactic neck irradiation indicated in patients with squamous cell carcinoma of the maxillary sinus? Int J Radiat Oncol Biol Phys 1997;39(2):283-289.

18. Tiwari R, Hardillo JA, Mehta D, Slotman B, Tobi H, Croonenburg E, van der Waal I, et al. Squamous cell carcinoma of maxillary sinus. Head Neck 2000;22(2):164169.

19. Stern SJ, Goepfert H, Clayman G, Byers R, Ang KK, el-Naggar AK, Wolf P. Squamous cell carcinoma of the maxillary sinus. Arch Otolaryngol Head Neck Surg 1993;119(9):964-969.

20. Giri SP, Reddy EK, Gemer LS, Krishnan L, Smalley SR, Evans RG. Management of advanced squamous cell carcinomas of the maxillary sinus. Cancer 1992;69(3):657661.

21. Jansen EP, Keus RB, Hilgers FJ, Haas RL, Tan IB, Bartelink H. Does the combination of radiotherapy and debulking surgery favor survival in paranasal sinus carcinoma? Int J Radiat Oncol Biol Phys 2000;48(1):27-35.

22. Chen AM, Daly ME, El-Sayed I, Garcia J, Lee NY, Bucci MK, Kaplan MJ. Patterns of failure after com- bined-modality approaches incorporating radiotherapy for sinonasal undifferentiated carcinoma of the head and neck. Int J Radiat Oncol Biol Phys 2008;70(2):338-343.

23. Hu YH, Tu GY, Qi YQ, Xu GS, Wu XL, Cai WM, Qin DX, et al. Comparison of pre- and postoperative radiation in the combined treatment of carcinoma of maxillary sinus. Int J Radiat Oncol Biol Phys 1982;8(6):10451049.

24. Jesse RH. Preoperative versus postoperative radiation in the treatment of squamous carcinoma of the paranasal sinuses. Am J Surg 1965;110(4):552-556.

25. Guo GF, Yang AK, Xie RH, Chen ZH, Wu QL, Ou SM, Liu WW, et al. [Prognostic analysis of 151 patients with maxillary sinus malignant neoplasms]. Ai Zheng 2004;23(11 Suppl):1546-1550.

26. Vermorken JB, van der Vijgh WJ, Klein I, Gall HE, Pinedo HM. Pharmacokinetics of free platinum species following rapid, 3-hr and 24-hr infusions of cis-diamminedichloroplatinum (II) and its therapeutic implications. Eur J Cancer Clin Oncol 1982;18(11):1069-1074.

27. Shibuya H, Suzuki S, Horiuchi J, Takagi M, Okuyama T, Suzuki H, Takeda M. Reappraisal of trimodal combination therapy for maxillary sinus carcinoma. Cancer 1982;50(12):2790-2794.

28. Tsujii H, Kamada T, Arimoto T, Mizoe J, Shirato H, Matsuoka Y, Irie G. The role of radiotherapy in the management of maxillary sinus carcinoma. Cancer 1986;57(12):2261-2266.

29. Inuyama Y, Fukuda S, Furuta Y, Yagi K, Nagahashi T, Chida E, Shirato H, et al. The role of chemotherapy in the treatment of head and neck cancer. Gan To Kagaku Ryoho 1997;24 Suppl 1(52-59.

30. Ogden GR. Second malignant tumours in head and neck cancer. BMJ 1991;302(6770):193-194.

31. Sirota DK, Eden AR, Biller HF. Multiple head and neck neoplasia following radiation for benign disease during childhood. J Surg Oncol 1988;38(2):101-103.

32. Cooper JS, Pajak TF, Rubin P, Tupchong L, Brady LW, Leibel SA, Laramore GE, et al. Second malignancies in patients who have head and neck cancer: incidence, effect on survival and implications based on the RTOG experience. Int J Radiat Oncol Biol Phys 1989;17(3):449456.

33. Kotwall C, Razack MS, Sako K, Rao U. Multiple primary cancers in squamous cell cancer of the head and neck. J Surg Oncol 1989;40(2):97-99.

34. Licciardello JT, Spitz MR, Hong WK. Multiple primary cancer in patients with cancer of the head and neck: second cancer of the head and neck, esophagus, and lung. Int J Radiat Oncol Biol Phys 1989;17(3):467-476.

35. Wynder EL, Dodo H, Bloch DA, Gantt RC, Moore OS. Epidemiologic investigation of multiple primary cancer of the upper alimentary and respiratory tracts. I. A retrospective study. Cancer 1969;24(4):730-739. 
36. Moore C. Cigarette smoking and cancer of the mouth, pharynx, and larynx. A continuing study. JAMA 1971;218(4):553-558.

37. Storm HH. Second primary cancer after treatment for cervical cancer. Late effects after radiotherapy. Cancer 1988;61(4):679-688.

38. Modan B, Baidatz D, Mart H, Steinitz R, Levin SG. Radiation-induced head and neck tumours. Lancet 1974;1(7852):277-279.

39. Wallner KE, Leibel SA, Wara WM. Squamous cell car- cinoma of the head and neck after radiation therapy for Hodgkin's disease. A report of two cases and a review of the literature. Cancer 1985;56(5):1052-1055.

40. Slaughter DP, Southwick HW, Smejkal W. Field cancerization in oral stratified squamous epithelium; clinical implications of multicentric origin. Cancer 1953;6(5):963-968.

41. Ogden GR, Cowpe JG, Green MW. Evidence of field change in oral cancer. Br J Oral Maxillofac Surg 1990;28(6):390-392. 